\title{
Changes in Adherence to the 24-Hour Movement Guidelines and Overweight and Obesity among Children in Northeastern Japan: A Longitudinal Study before and during the COVID-19 Pandemic
}

\author{
Hyunshik Kim ${ }^{1}{ }^{\oplus}$, Jiameng Ma ${ }^{1} \mathbb{D}$, Junghoon $\operatorname{Kim}^{2}{ }^{\circledR}$, Daolin $\mathrm{Xu}^{1}$ and Sunkyoung Lee ${ }^{3, *}$ \\ 1 Faculty of Sports Science, Sendai University, Satsumasendai 989-1693, Japan; hs-kim@sendai-u.ac.jp (H.K.); \\ jm-ma@sendai-u.ac.jp (J.M.); s20510212@sendai-u.ac.jp (D.X.) \\ 2 Sports and Exercise Medicine Laboratory, Korea Maritime and Ocean University, 727 Taejong-ro, Yeongdo-gu, \\ Busan 49112, Korea; junghoonkim@kmou.ac.kr \\ 3 Department of Life Physical Education, Myongji University, 34 Geobukgol-ro, Seodaemun-gu, \\ Seoul 03674, Korea \\ * Correspondence: iamlsk@mju.ac.kr; Tel.: +82-2-300-1817
}

check for

updates

Citation: Kim, H.; Ma, J.; Kim, J.; Xu, D.; Lee, S. Changes in Adherence to the 24-Hour Movement Guidelines and Overweight and Obesity among Children in Northeastern Japan: A Longitudinal Study before and during the COVID-19 Pandemic. Obesities 2021, 1, 167-177. https:// doi.org/10.3390/obesities1030015

Academic Editor: Gerard A. Kennedy

Received: 27 October 2021

Accepted: 24 November 2021

Published: 27 November 2021

Publisher's Note: MDPI stays neutral with regard to jurisdictional claims in published maps and institutional affiliations.

Copyright: (C) 2021 by the authors. Licensee MDPI, Basel, Switzerland. This article is an open access article distributed under the terms and conditions of the Creative Commons Attribution (CC BY) license (https:/ / creativecommons.org/licenses/by/ $4.0 /)$.

\begin{abstract}
There are few studies comparing adherence to Canadian 24-hour Movement Guidelines (24-h MG) before and during the COVID-19 pandemic and exploring the pandemic's effect on childhood obesity. This survey-based 2-year study investigated changes in obesity and adherence to the 24-h MG in children before and during the COVID-19 pandemic. Data were collected at two points in time: pre-COVID-19 (May 2019; T1; $n=247$ ) and during-COVID-19 (May 2021; T2; $n=171$ ). Participants were healthy elementary school children aged between 6-12 years in northeastern Japan. The questionnaire comprised items on physical activity, screen time, sleep duration, adherence to the 24-h MG, and anthropometric and demographic characteristics. Among all participants, a statistically significant difference $(p<0.001)$ between the average body mass index at T1 $\left(\mathrm{M}=16.06 \mathrm{~kg} / \mathrm{m}^{2}\right.$, $\left.\mathrm{SD}=2.08 \mathrm{~kg} / \mathrm{m}^{2}\right)$ and T2 $\left(\mathrm{M}=18.01 \mathrm{~kg} / \mathrm{m}^{2}, \mathrm{SD}=3.21 \mathrm{~kg} / \mathrm{m}^{2}\right)$ was observed, where $17.8 \%$ were overweight and obese at T1 and $24 \%$ at T2, and $10.9 \%$ adhered to all $24 \mathrm{~h} \mathrm{MG}$ at T1 and $4.1 \%$ at T2 To prevent obesity in children during the COVID-19 pandemic, environmental changes should be evaluated and appropriate preventive measures taken, including pro-community health programs that encourage parent-children outdoor activities.
\end{abstract}

Keywords: COVID-19; obesity; overweight; sleep duration; screen time; physical activity; longitudinal survey

\section{Introduction}

In late December 2019, the first reports on what would come to be known as the coronavirus disease 2019 (COVID-19), caused by the severe acute respiratory syndrome coronavirus-2 (SARS-CoV-2), began to emerge. Then, in March 2020, the World Health Organization (WHO) declared the COVID-19 pandemic [1]. This pandemic has had profound effects on the morbidity and mortality of populations worldwide, ignoring boundaries related to race, age, and wealth $[2,3]$. Globally, countries have implemented different measures to prevent the spread of COVID-19 and reduce the burden on health care systems, including restrictions to access public facilities/schools, quarantine, and social distancing [4]. On April 16, 2020, the Government of Japan declared a state of emergency in major cities countrywide [5], temporarily closing all elementary, middle, and high schools, actively encouraging social distancing, and restricting social gatherings in local communities and the use of sports facilities, playgrounds, and parks. Although these measures have reduced the spread of COVID-19 worldwide, they have concomitantly increased health-risk behaviors [6], including changes in levels of physical activity, sedentary behavior, dietary 
habits, sleep duration, and children's mental health [7-9]. In 2016, the Canadian Society for Exercise Physiology (CSEP) suggested the Canadian 24-hour Movement Guidelines (24-h MG) for children and adolescents aged from 5-17 years [10]; these guidelines advise that, to promote and maintain optimal health, children must increase physical activity levels, reduce sedentary behavior, and sleep for a sufficient number of hours within a set time of the day. These daily movement behaviors (i.e., physical activity, sedentary behavior, and sleep) have been shown to affect children's immune system and their physical, psychological, and mental health [11-14].

Within the scope of this discussion about health and sedentary behavior, the topic of obesity should be broached. Although obesity rates tend to be lower in children than in adults, the rate of obesity in children is increasing at a faster pace. Recently, a global study reported that about $5 \%$ of children are obese, with this rate being $5.2 \%$ in Japan [15-17]. Studies show that children who are overweight or obese are more likely to become obese adults, and are at greater risk of developing hypertension and diabetes mellitus. Additionally, these weight-related conditions were shown to longitudinally affect physical and mental health $[18,19]$. Thus, considering these physical and psychological effects, it can be argued that studies on the prevention of obesity and overweight are fundamental to ensure better health status for children across their lifetime.

Undoubtedly, the COVID-19 pandemic has changed the daily lives of children, families, and communities. Before the COVID-19 pandemic, millions of children and adolescents had never been forced to spend the bulk of their days at home, away from their friends and peers. During the COVID-19 pandemic, children showed significantly lower levels of outdoor and group-based physical activities, leading to an increased amount of time at home and, subsequently, unhealthy habits (e.g., excessive sedentary behavior) $[20,21]$. Although quarantine measures to prevent the spread of COVID-19 have increased the risk of weight gain and obesity in children worldwide [22,23], the effects of the COVID-19 pandemic on childhood obesity have yet to be comprehensively explored. There are a lack of studies comparing adherence to the 24-h MG before and during the COVID-19 pandemic.

Thus, this study aimed to investigate changes in obesity and in adherence to the 24-h MG among elementary school children in northeastern Japan, using longitudinal data collected before and during the COVID-19 pandemic.

\section{Materials and Methods}

\subsection{Research Design and Participants}

In this 2-year longitudinal study, data were collected before and during the during COVID-19 pandemic (in 2019 and 2021). In this study, we conducted a survey targeting students in all grades of an elementary school in Ohira-mura (population: 5918 persons; surface area: $60.32 \mathrm{~km}^{2}$ ) located in Miyagi Prefecture. In addition, study participants were healthy elementary school children, aged between 6-12 years old, without any physical or mental disability (Figure 1). After excluding 10 questionnaires that were not completed and 7 children who did not agree to participate, 372 children were enrolled in the study. Specifically, in May 2019 (T1; pre-COVID-19 pandemic), they completed the first survey administration, and in May 2021 (T2; during COVID-19 pandemic), they completed second; after excluding the data from 125 children who had graduated from school by 2020 and who did not partake in T2 survey, the T1 $(n=247)$ and T2 data were compared. Furthermore, at $\mathrm{T} 2$, only 247 (of the 381 children who responded at T1, 63.4\%) completed the questionnaire, with 2 transfer school children, where this number excludes 28 children who did not agree to participate and 46 who did not complete the questionnaire. (T2; $n=171,43.9 \%$ ).

In accordance with the Declaration of Helsinki of 1975, the children and their guardians provided written informed consent before study participation, and only the data of those who provided such consent were included in the final analysis. The study was approved by the Sendai University Ethics Committee, Faculty of Sports Science (SU29-22). 


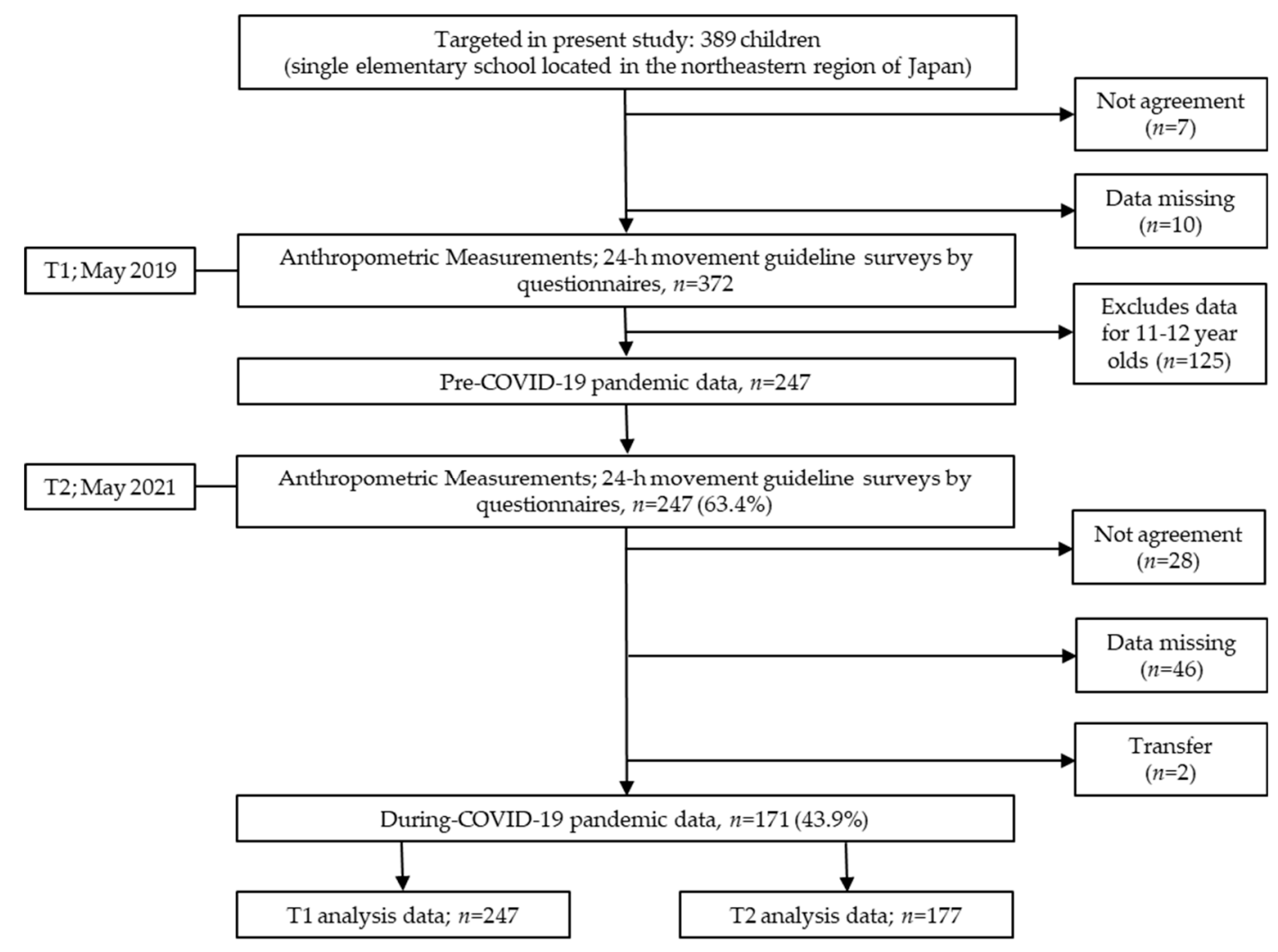

Figure 1. Flow chart of participants and protocol of longitudinal study.

\subsection{Measurements}

\subsubsection{Physical Activity}

Physical activity levels were assessed using the self-reported Japanese version of the Health Behavior in School-aged Children (HBSC), published by the WHO [24,25]. For this measurement tool, moderate to vigorous physical activity (MVPA) is defined as "any kind of physical activity that increases your heart rate and make you breathe hard some of the time (including physical education time, exercising, sport training and various regular daily activities such as brisk walking, hiking and excursion)." All students answered to one item about physical activity, and children below 12 years old completed the questionnaires with the help of parents/guardians: "Over the past 7 days (from Monday to Sunday), how many days were you physically active for at least $60 \mathrm{~min}$ in the day?" The response scale for this question ranged from 0-7 (0-7 days). Based on prior research [10], participants who reported 7 days of MVPA were deemed to have met the standard for physical activity set forth in the $24 \mathrm{~h} \mathrm{MG}$. For analysis, this variable was dichotomized into 1 (7 days of MVPA) and 0 (other answers).

\subsubsection{Screen Time}

In this study, screen time was defined as the time spent engaging in screen-based behaviors, including recreational, stationary, sedentary, and active screen time [26]. This construct was measured by asking students about the amount of time they spent watching $\mathrm{TV} /$ videos and/or using electronic devices (e.g., smartphones and tablets) in the past week. Specifically, there were two questions: (1) "How much time (during weekdays and the weekend) do you spend on a day watching TV or videos, on average?" and (2) "How much time (during weekdays and the weekend) do you use electronic devices (e.g., smartphones, tablets, and computers) on average?" Average screen time per day for weekdays and the weekend was recorded separately; again, children below 12 years of age completed the questionnaires with the help of their parents/guardians. Following the procedures of prior research [27], average daily screen time was calculated using the following formula: 
average daily screen time $=[($ screen time during weekdays $\times 5)+($ screen time during the weekend $\times 2)] / 7$.

\subsubsection{Sleep Duration}

Sleep duration was investigated using the following questions: (1) "At what time did you go to bed in the last week, on average?" and (2) "At what time did you wake up in the last week, on average?" The formula for daily sleep duration was: daily sleep time $=$ bedtime - wake-up time.

\subsubsection{Adherence to the 24-h Movement Guidelines}

Following past research [10], to evaluate the adherence to the 24-h MG among study participants, the following standards for each movement behavior were applied: (1) physical activity: MVPA for $60 \mathrm{~min}$ per day; (2) screen time: less than $2 \mathrm{~h}$ of screen time per day; (3) sleep duration: 9-11 h of sleep within $24 \mathrm{~h}$.

\subsubsection{Anthropometric Measurements}

The body height (BSM370, InBody Co., Ltd. Tokyo, Japan) and weight (WB-150P, Tanita Co., Ltd. Tokyo, Japan) were measured without shoes and with light clothing to the nearest $0.1 \mathrm{~cm}$ and $0.1 \mathrm{~kg}$, respectively. In addition, it was not limited to the position of participants and fasting status, and measurements were made under the same conditions as usual. For every child, the standard deviation scores (z-scores) for height, weight, and body mass index (BMI) were calculated at both T1 and T2. For BMI, the $z$-score was calculated according to the growth criteria listed by the WHO [28]. For weight, categories and allocation of participants to these categories were based on the $z$-scores of their BMIs, as follows: obese (BMI $z$-score $\geq 1.645$ ), overweight $(1.036 \leq$ BMI $z$-score $<1.645)$, normal weight $(-1.645 \leq$ BMI $z$-score $<1.036)$, and underweight (BMI $z$-score $<-1.645)$, following procedures of past research [29].

\subsubsection{Demographic Variables}

The following sociodemographic variables were also assessed: sex, age, bedtime, wake time, weight, height, and membership in sports clubs (obtained from the children and their parents).

\subsection{Statistical Analysis}

To analyze changes in continuous variables (e.g., age, bedtime, wake-up time, height, weight, and BMI) between T1 (pre-COVID-19 pandemic) and T2 (during COVID-19 pandemic), $t$-tests were performed. Chi-square tests were used to analyze categorical variables (e.g., sex and membership status in sports clubs). To examine changes in adherence to the 24-h MG (i.e., physical activity, screen time, and sleep duration) between T1 and T2, paired-sample $t$-tests were used.

To check the frequency of adherence to the movement behavior standards (i.e., standards for physical activity, screen time, and sleep duration) and to the combinations of these standards (physical activity + screen time; physical activity + sleep duration; screen time + sleep duration; and physical activity + screen time + sleep duration), frequency analyses were conducted. The proportion of children who adhered to the 24-h MG for each movement behavior standard and their combinations was calculated. The Wilcoxon Signed-rank test was conducted to evaluate the changes per weight status among those adherent to each of the movement behavior standards and their combinations between T1 and T2.

Statistical analyses were performed using SPSS, version 26.0 (IBM, Armonk, NY, USA), and the statistical significance level was set at $p<0.05$.

\section{Results}

In total, students who partook in both $\mathrm{T} 1$ and $\mathrm{T} 2$ had their data analyzed. Table 1 shows participants' general characteristics at T1 and T2. Participants' mean age at T1 and 
$\mathrm{T} 2$ were 7.61 years $(\mathrm{SD}=0.93$ years) and 9.67 years $(\mathrm{SD}=1.22$ years), respectively; their mean weight was $23.72 \mathrm{~kg}(\mathrm{SD}=5.26 \mathrm{~kg})$ and $34.01 \mathrm{~kg}(\mathrm{SD}=9.15 \mathrm{~kg})$, respectively; and their mean height was $120.66 \mathrm{~cm}(\mathrm{SD}=7.24 \mathrm{~cm})$ and $136.48 \mathrm{~cm}(\mathrm{SD}=9.17 \mathrm{~cm})$, respectively.

Table 1. Descriptive characteristics of participants.

\begin{tabular}{|c|c|c|c|}
\hline & Pre-COVID-19 & During-COVID-19 & \multirow{2}{*}{$p$-Value } \\
\hline & $n=247$ (2019 Data) & $n=171$ (2021 Data) & \\
\hline & $n(\%)$ or mean $\pm \mathrm{SD}^{\mathrm{a}}$ & $n(\%)$ or mean $\pm \mathrm{SD}^{\mathrm{a}}$ & \\
\hline Sex (boys) & 55.1 & 56.7 & 0.407 \\
\hline Sports club (join) & 26.5 & 27.9 & 0.818 \\
\hline Age (years) & $7.61 \pm 0.93$ & $9.67 \pm 1.22$ & $<0.001$ \\
\hline Height $(\mathrm{cm})$ & $120.66 \pm 7.24$ & $136.48 \pm 9.17$ & $<0.001$ \\
\hline Weight (Kg) & $23.72 \pm 5.26$ & $34.01 \pm 9.15$ & $<0.001$ \\
\hline $\operatorname{BMI}\left(\mathrm{Kg} / \mathrm{m}^{2}\right)$ & $16.06 \pm 2.08$ & $18.01 \pm 3.21$ & $<0.001$ \\
\hline BMI z-score & $-0.01 \pm 0.95$ & $0.29 \pm 1.04$ & 0.007 \\
\hline Bedtime (minutes) & $1285.36 \pm 37.52$ & \multirow{2}{*}{$\begin{array}{c}1304.26 \pm 43.18 \\
387.63+29.26\end{array}$} & $<0.001$ \\
\hline Wakeup time (minutes) & $393.19 \pm 23.78$ & & 0.069 \\
\hline
\end{tabular}

Note: a SD, standard deviation. $p$-values were calculated using $t$-test for continuous variables and chi-square test for categorical variables.

A statistically significant difference $(p<0.001)$ between the average BMI at T1 $\left(\mathrm{M}=16.06 \mathrm{~kg} / \mathrm{m}^{2}, \mathrm{SD}=2.08 \mathrm{~kg} / \mathrm{m}^{2}\right)$ and at $\mathrm{T} 2\left(\mathrm{M}=18.01 \mathrm{~kg} / \mathrm{m}^{2}, \mathrm{SD}=3.21 \mathrm{~kg} / \mathrm{m}^{2}\right)$ was found, as well as a statistically significant difference between the mean BMI $z$-scores at $\mathrm{T} 1(\mathrm{M}=-0.01, \mathrm{SD}=0.95)$ and at $\mathrm{T} 2(\mathrm{M}=0.29, \mathrm{SD}=1.04)(p<0.003)$. In addition, a significantly greater sleep duration at $\mathrm{T} 2(\mathrm{M}=1304.26 \mathrm{~min}, \mathrm{SD}=43.18 \mathrm{~min})$ than at $\mathrm{T} 1$ $(\mathrm{M}=1285.36 \mathrm{~min}, \mathrm{SD}=37.52 \mathrm{~min})$ was observed.

Table 2 depicts changes in physical activity, screen time, and sleep duration between T1 and T2. MVPA was found to be significantly $(p<0.001)$ lower at T2 $(\mathrm{M}=4.49$ days, $\mathrm{SD}=2.39$ days $)$ than at $\mathrm{T} 1(\mathrm{M}=5.79$ days, $\mathrm{SD}=2.53$ days $)$. There was no significant difference between $\mathrm{T} 1$ and $\mathrm{T} 2$ values for screen time watching TV/videos on both weekdays and weekends. Screen time using electronic devices (e.g., smartphones and tablets) was significantly higher at T2 than at T1 $(p<0.001)$. Sleep duration was significantly $(p<0.001)$ lower at $\mathrm{T} 2(\mathrm{M}=523.44 \mathrm{~min}, \mathrm{SD}=38.89 \mathrm{~min})$ than at $\mathrm{T} 1(\mathrm{M}=547.68 \mathrm{~min}, \mathrm{SD}=36.79 \mathrm{~min})$.

Table 2. Change of physical activity, screen time, and sleep pre- and during-COVID-19 pandemic.

\begin{tabular}{|c|c|c|c|c|c|}
\hline & $\begin{array}{l}\text { Pre-COVID-19 } \\
\quad n=247\end{array}$ & $\begin{array}{l}\text { During-COVID-19 } \\
n=171\end{array}$ & \multirow{2}{*}{$\begin{array}{l}\text { Mean Change } \\
\quad(95 \% \text { CI })\end{array}$} & \multirow[t]{2}{*}{$t$} & \multirow[t]{2}{*}{$p$-Value } \\
\hline & Mean (SD) ${ }^{a}$ & Mean (SD) ${ }^{a}$ & & & \\
\hline \multicolumn{6}{|l|}{ Physical activity (day/week) } \\
\hline MVPA & $5.79(2.53)$ & $4.49(2.39)$ & $1.30(0.65,1.94)$ & 4.004 & $<0.001$ \\
\hline \multicolumn{6}{|l|}{ Screen time (min/day) } \\
\hline TV/DVD (weekdays) & $90.13(50.56)$ & $88.75(65.01)$ & $1.37(-12.67,15.42)$ & 0.194 & 0.847 \\
\hline TV/DVD (weekend) & $126.77(64.04)$ & $128.59(90.11)$ & $-1.81(-21.13,16.51)$ & -0.190 & 0.845 \\
\hline Smartphone/tablet (weekdays) & $18.93(43.11)$ & $56.26(65.01)$ & $-37.32(-50.75,-23.90)$ & -5.495 & $<0.001$ \\
\hline Smartphone/tablet (weekend) & $31.57(67.45)$ & $75.95(73.39)$ & $-44.38(-61.34,-27.41)$ & -5.171 & $<0.001$ \\
\hline Total screen time (weekdays) & $108.41(61.50)$ & $143.64(92.88)$ & $-35.23(-54.26,-16.20)$ & -3.659 & $<0.001$ \\
\hline Total screen time (weekend) & $157.36(84.06)$ & $202.77(114.98)$ & $-45.40(-69.11,-21.69)$ & -1.663 & $<0.001$ \\
\hline \multicolumn{6}{|l|}{ Sleep (min/day) } \\
\hline Sleep duration & $547.68(23.78)$ & $523.44(38.89)$ & $24.23(15.56,32.91)$ & 5.523 & $<0.001$ \\
\hline
\end{tabular}

Note: ${ }^{a} \mathrm{SD}$, standard deviation; ${ }^{\mathrm{b}} \mathrm{MVPA}$, moderate to vigorous physical activity; $p$ for difference was calculated using $t$-test for categorical variables.

Table 3 shows the changes in weight status among children who adhered to each of the movement behavior standards and their combinations between T1 and T2. Among all participants, $75.7 \%$ had a normal body weight at $\mathrm{T} 1$ and $76.0 \%$ at $\mathrm{T} 2,17.8 \%$ were overweight or obese at $\mathrm{T} 1$ and $24 \%$ at $\mathrm{T} 2$, and $6.5 \%$ were underweight at $\mathrm{T} 1$. 
Upon analyzing the changes between $\mathrm{T} 1$ and $\mathrm{T} 2$ for 24-h movement guidelines among participants with a normal body weight, physical activity was found to be significantly $(p<0.013)$ lower at T2 $35.1 \%$ than at T1 56.6\%. Sleep duration was also found to be significantly lower $(p<0.001)$. Regarding the combinations, statistically significant differences for physical activity + screen time $(p<0.007)$, physical activity + sleep duration $(p<0.001)$, and screen time + sleep duration $(p<0.024)$ were also found.

The proportions of children who adhered to the 24-h MG (i.e., for physical activity, screen time, and sleep duration) at $\mathrm{T} 1$ and $\mathrm{T} 2$ are shown in Figure 2. At T1, approximately $10.9 \%$ of the children adhered to all $24-\mathrm{h} \mathrm{MG}$, and at T2, only $4.1 \%$ did. Upon analyzing the changes between $\mathrm{T} 1$ and $\mathrm{T} 2$ for movement behaviors and their combinations among overweight and obese participants, no statistically significant changes for screen time and for the combination of physical activity + screen time were found. For the other behaviors and combinations, values that were statistically significantly lower at $\mathrm{T} 2$ than at $\mathrm{T} 1$ were obtained.

(a) Pre-Covid-19

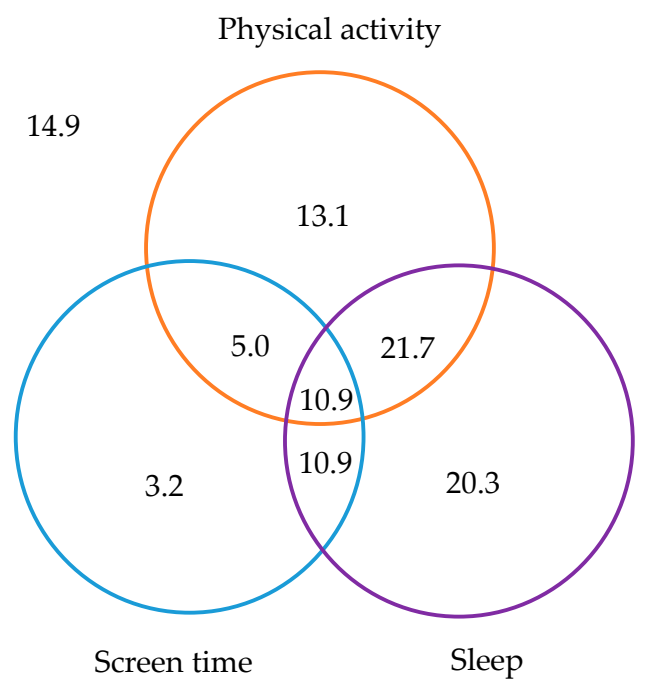

(b) During-Covid-19

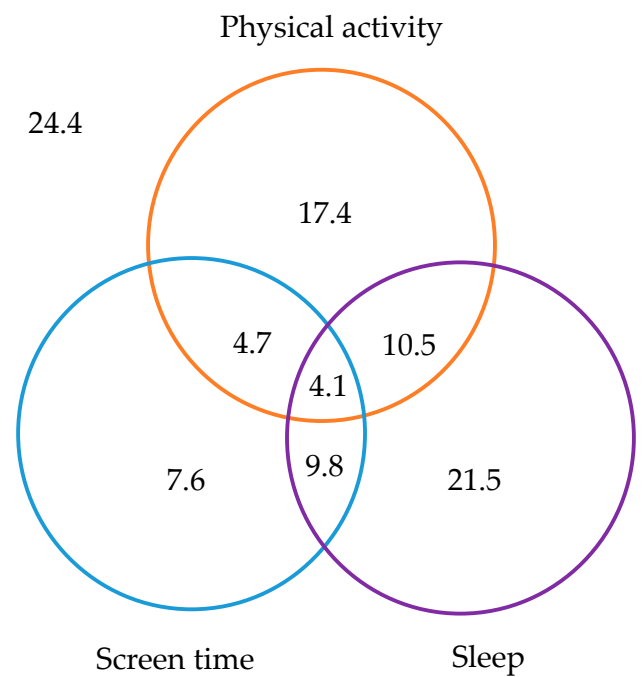

Figure 2. Percentages meeting 24-h movement guidelines among (a) pre-COVID-19 $(n=247)$ and (b) during-COVID-19 ( $n=171)$ Japanese elementary school children. Venn diagram: The numbers within each circle are added to the proportion of children meeting each individual guideline (pre-COVID-19: $56.6 \%$ for physical activity, $30.2 \%$ for screen time, and $66.1 \%$ for sleep duration; during- COVID-19: 35.1\% for physical activity, $22.0 \%$ for screen time, and 45.7\% for sleep duration). The total nonoverlap area of each circle represents the proportion of children meeting one of the three guidelines (pre-COVID-19: $13.1 \%+3.2 \%+20.3 \%=36.6 \%$; during-COVID-19: $17.4 \%+7.6 \%+21.5 \%=46.5 \%)$. The total overlap areas of the two circles represent the proportion of children meeting two guidelines out of the three guidelines (pre-COVID-19: $5.0 \%+21.7 \%+$ $10.9 \%=37.6 \%$; during-COVID-19: $4.7 \%+9.8 \%+10.5 \%=25.0 \%$ ). The overlap area of three circles represents the proportion of children meeting all three guidelines (pre-COVID-19: 10.9\%; during- COVID-19: 4.1\%). The outside area of the circle represents the proportion of children not meeting any of the guidelines (pre-COVID-19: 14.9\%; during- COVID-19: 24.4\%).

Table 3. Changes in adherence to 24-h MG pre- and during-COVID-19 pandemic according to overweight and obesity.

\begin{tabular}{|c|c|c|c|c|c|}
\hline \multirow{2}{*}{ Meeting Recommendations ${ }^{\text {a }}$} & \multicolumn{2}{|c|}{ Pre-COVID-19 } & \multicolumn{2}{|c|}{ During-COVID-19 } & \multirow{2}{*}{$p$-Value } \\
\hline & $n$ & $\%$ & $n$ & $\%$ & \\
\hline Normal weight $(-1.645<\text { BMI } z \text {-scores }<1.036)^{b}$ & \multicolumn{2}{|c|}{$n=187(75.7 \%)$} & \multicolumn{2}{|c|}{$n=130(76.0 \%)$} & \\
\hline None & 23 & 12.6 & 30 & 22.6 & 0.095 \\
\hline Physical activity & 99 & 56.6 & 39 & 35.1 & 0.013 \\
\hline Screen time & 54 & 30.2 & 29 & 22.0 & 0.170 \\
\hline Sleep duration & 119 & 66.1 & 59 & 45.7 & $<0.001$ \\
\hline Physical activity + screen time & 32 & 17.7 & 9 & 6.8 & 0.007 \\
\hline Physical activity + sleep duration & 62 & 34.1 & 22 & 16.8 & $<0.001$ \\
\hline Screen time + sleep duration & 41 & 22.7 & 18 & 13.5 & 0.024 \\
\hline Physical activity + screen time + sleep duration & 19 & 9.5 & 5 & 3.8 & 0.071 \\
\hline
\end{tabular}


Table 3. Cont.

\begin{tabular}{|c|c|c|c|c|c|}
\hline \multirow{2}{*}{ Meeting Recommendations ${ }^{\text {a }}$} & \multicolumn{2}{|c|}{ Pre-COVID-19 } & \multicolumn{2}{|c|}{ During-COVID-19 } & \multirow{2}{*}{$p$-Value } \\
\hline & $n$ & $\%$ & $n$ & $\%$ & \\
\hline Overweight/obesity (BMI $z$-scores $>1.036)^{b}$ & \multicolumn{2}{|c|}{$n=44(17.8 \%)$} & \multicolumn{2}{|c|}{$n=41(24.0 \%)$} & \\
\hline None & 11 & 27.5 & 13 & 33.3 & 0.782 \\
\hline Physical activity & 13 & 35.1 & 10 & 26.4 & 0.763 \\
\hline Screen time & 9 & 24.3 & 9 & 23.1 & 0.913 \\
\hline Sleep duration & 23 & 57.5 & 15 & 38.5 & 0.104 \\
\hline Physical activity + screen time & 4 & 9.1 & 4 & 7.4 & 0.705 \\
\hline Physical activity + sleep duration & 9 & 22.5 & 3 & 7.7 & 0.052 \\
\hline Screen time + sleep duration & 6 & 15.0 & 6 & 15.4 & 0.983 \\
\hline Physical activity + screen time + sleep duration & 3 & 6.8 & 1 & 2.6 & 0.317 \\
\hline
\end{tabular}

Note: a Meeting the recommendations is defined as $60 \mathrm{~min} /$ day of moderate-to-vigorous physical activity, no more than $120 \mathrm{~min} /$ day for screen time, and between 9 and $11 \mathrm{~h}$ /day for sleep duration [10]. ${ }^{\mathrm{b}}$ Body mass index.

\section{Discussion}

The present study was the first 2-year longitudinal study to assess the effects of the COVID-19 pandemic on physical activity, screen time, sleep duration, and overweight and obesity among elementary school students in Japan.

The study's findings indicated that the overweight and obesity rates increased significantly among Japanese children during the COVID-19 pandemic compared with before it. This result is consistent with those of previous studies exploring the effects of the COVID-19 pandemic on obesity in adults and in children across different countries [30-33]. Thus, the results and discussion suggest that the COVID-19 pandemic has had great effects on Japanese children's lifestyle, which may have facilitated obesity in childhood. Research shows that policies to prevent the spread of COVID-19 (e.g., lockdown) may have negative effects (e.g., increased sleep duration and decreased physical activity) in children and increase their risk of weight gain and obesity [23].

In this study, although the obesity rate among children with normal weight showed no changes during the COVID-19 pandemic, this rate increased significantly among children who were overweight or obese during the same period. The excessive weight gained during the COVID-19 pandemic by these children may be difficult to lose. Additionally, research shows that, similar to adults, overweight or obese children have a high risk of developing various non-contagious diseases [18]. Thus, to prevent obesity in children during the COVID-19 pandemic, it may be necessary to assess environmental changes and take appropriate preventive measures.

To compare each variable under the 24-h MG in this study, participants were divided into overweight or obese and normal weight groups. Among children with normal weight, it was observed that physical activity, sleep duration, physical activity + screen time, physical activity + sleep duration, and screen time + sleep duration were all significantly correlated to each other. In contrast, among children who were overweight or obese, no significant changes were found in adherence to each of these factors. Moreover, in the pre-COVID-19 period, $86.9 \%$ of the children in the sample adhered to one or more of the recommendations, while only $13.1 \%$ of the children adhered to all three recommendations under the 24-h MG. Although this adherence rate to all 24-h MG standards in the study was lower than that in a previous study conducted with Japanese preschoolers [27], it was similar to the rate in a study conducted in a Japanese elementary school [34].

Additionally, physical activity and sleep duration significantly decreased and screen time significantly increased during the COVID-19 pandemic compared to their values before the pandemic. The findings on physical activity are consistent with those of other studies on children and adolescents aged 5-17 years in the United States of America [7], Brazil, Chile [35], Italy [34], and China [36], all of which established different levels of restriction related to the COVID-19 pandemic. In school, children often engage in organized sports, games, and dance practices, as well as spending time in playgrounds and parks 
after school, promoting their physical activity [37]. This indicates that the restrictions on the use of public and play spaces during the COVID-19 pandemic may have resulted in children having fewer opportunities to engage in physical activities. In fact, outdoor play has been shown to provide children with health-related benefits, such as improved exercise ability and increased levels of physical activity [38]. Concurring with this study's findings, research conducted with children and adolescents during the COVID-19 pandemic reported that outdoor play time decreased on weekdays and weekends [39], and that this decreased outdoor play time leads to significantly lower levels of MVPA and light physical activity. Furthermore, children's physical activity and sedentary behavior have been found to be strongly correlated with the participation of parents or role models in these activities [40]. Thus, the importance of developing and implementing family-oriented health programs around residential areas and local communities, allowing parents and children to partake in outdoor activities together, is evident.

Although adherence to the 24-h MG for screen time did not significantly change, electronic device usage (e.g., smartphones and tablets) during leisure time significantly increased during the COVID-19 pandemic compared with before the pandemic. Studies conducted in China [41], Italy [23], and Canada [21] reported similar findings. Thus, following the general trend across various countries, measures such as lockdowns and social distancing, as well as parental concerns regarding their children contracting COVID-19 in outdoor environments, have led to a significant decrease in outdoor play time and an increase in screen-based leisure time among Japanese children. Additionally, the number of online classes has gradually increased during the COVID-19 pandemic. Although the use of screens in online learning for children can improve self-esteem, social skills, and knowledge [42], there is a need for interventions focused on reducing screen time for leisure activities (e.g., gaming and watching videos). Furthermore, since screen time in such contexts is directly related to schoolwork, restricting the screen time of children might be difficult [43]. Therefore, future intervention-based studies should consider parental restrictions (e.g., restricting screen time and imposing rules) and support in their investigations.

In the sample of the present study, the effects of the COVID-19 pandemic on sleep duration differed greatly from those on physical activity and screen time. In a systematic literature review that analyzed the influence of COVID-19 on movement behaviors of children and youth [44], studies presented conflicting results: some reported an increase in sleep duration, others a decrease, others did not report any changes, and a Japanese study conducted with preschoolers showed an increase in sleep duration during the COVID-19 pandemic [45]. In studies reporting an increase regarding this variable, it seems that the quarantine measures were the reason for this change $[23,35,46]$. It may also be that the absence of school commuting could increase sleep duration in children; in fact, across Japan, all schools were closed from February to May 2020, to prevent the spread of COVID-19 [47], so school life returned to normal only after this period. Thus, it seems that the COVID-19 pandemic did not have profound effects on sleep duration, denoting that future studies should assess the underlying reasons for the delayed bedtime experienced by children in this sample during the COVID-19 pandemic. Regarding changes in adherence to the 24-h MG for sleep duration, this study's findings support those of prior research showing that such adherence decreased during the COVID-19 pandemic [35]. A study shows that sleep disorders may have significant effects on attention span, emotional health, immune function, and academic achievement in children [48]. Future studies should assess both sleep duration and quality.

Like any other research, this study had certain limitations that need to be considered while interpreting its findings. First, this study was targeted at children in the northeastern region of Japan, so it is unclear whether its findings can be generalized to children across Japan. Secondly, the present study results are drawn from two revelations of a single questionnaire. Thirdly, the data were mostly dependent on the parents' responses. The psychological state of the parents may have affected their responses as well as the assessment of the behaviors of their children [49]. 


\section{Conclusions}

The findings of the present study demonstrated that among children aged 6-12 years in northeastern Japan, the overweight and obesity rate increased, the physical activity and sleep duration decreased, and screen time increased during the COVID-19 pandemic compared with before the pandemic. Moreover, children's adherence to the 24-h MG for some combinations of movement-related behaviors (i.e., physical activity + screen time, physical activity + sleep duration, and screen time + sleep duration) was significantly lower during the COVID-19 pandemic. The findings of this study may be a useful aid for future public health policies and programs.

Author Contributions: Conceptualization, S.L. and H.K.; methodology, J.M., J.K. and H.K.; validation, J.M., H.K., J.K., D.X., and S.L.; formal analysis, J.K., H.K.; data curation, D.X., H.K. and S.L.; writing — original draft preparation, D.X., H.K., and J.K.; writing—review and editing, S.L.; visualization, H.K. and J.K.; supervision, S.L. and H.K.; project administration, S.L. and H.K.; funding acquisition, J.M., S.L. and H.K. All authors have read and agreed to the published version of the manuscript.

Funding: This work was supported by JSPS KAKENHI Grant Number JP 21K11555, and the International Joint Research Project in Sendai University (Grant Number: 2018-0025).

Institutional Review Board Statement: The study was conducted according to the guidelines of the Declaration of Helsinki and approved by the Institutional Review Board of the Sendai University Ethics Committee of the Faculty of Sports Science (IRB Number: SU29-22).

Informed Consent Statement: Informed consent was obtained from all subjects involved in the study.

Data Availability Statement: Data is contained within the article.

Conflicts of Interest: The authors declare no conflict of interest. The funders had no role in the study design; in the collection, analyses, or interpretation of data; in the writing of the manuscript, or in the decision to publish the results.

\section{References}

1. World Health Organization. WHO Director-General's Opening Remarks at the Media Briefing on COVID-19-11. 2020. Available online: https:/ /www.who.int/director-general/speeches/detail/who-director-general-s-opening-remarks-at-themedia-briefing-on-covid-19---11-march-2020 (accessed on 2 September 2021).

2. Banerjee, A.; Pasea, L.; Harris, S.; Gonzalez-Izquierdo, A.; Torralbo, A.; Shallcross, L.; Noursadeghi, M.; Pillay, D.; Sebire, N.; Holmes, C.; et al. Estimating excess 1-year mortality associated with the COVID-19 pandemic according to underlying conditions and age: A population-based cohort study. Lancet 2020, 395, 1715-1725. [CrossRef]

3. Li, Q.; Guan, X.; Wu, P.; Wang, X.; Zhou, L.; Tong, Y.; Ren, R.; Leung, K.S.M.; Lau, E.H.Y.; Wong, J.Y.; et al. Early transmission dynamics in Wuhan, China, of novel coronavirus-infected pneumonia. N. Engl. J. Med. 2020, 382, 1199-1207. [CrossRef]

4. Huizar, M.I.; Arena, R.; Laddu, D.R. The global food syndemic: The impact of food insecurity, Malnutrition and obesity on the healthspan amid the COVID-19 pandemic. Prog. Cardiovasc. Dis. 2020, 64, 105-107. [CrossRef] [PubMed]

5. Looi, M.K. Covid-19: Japan prepares to extend state of emergency nationwide as "untraceable" cases soar. BMJ 2020, 369, 1543. [CrossRef] [PubMed]

6. López-Bueno, R.; Calatayud, J.; Casaña, J.; Casajús, J.A.; Smith, L.; Tully, M.A.; Andersen, L.L.; López-Sánchez, G.F. COVID-19 confinement and health risk behaviors in Spain. Front. Psychol. 2020, 11, 1426. [CrossRef] [PubMed]

7. Dunton, G.F.; Bridgette, D.; Shirlene, D.W. Early effects of the COVID-19 pandemic on physical activity and sedentary behavior in children living in the U.S. BMC Public Health 2020, 20, 1351. [CrossRef]

8. Di Renzo, L.; Gualtieri, P.; Pivari, F.; Soldati, L.; Attinà, A.; Cinelli, G.; Leggeri, C.; Caparello, G.; Barrea, L.; Scerbo, F.; et al. Eating habits and lifestyle changes during COVID-19 lockdown: An Italian survey. J. Transl. Med. 2020, 18, 229. [CrossRef] [PubMed]

9. Wang, C.; Pan, R.; Wan, X.; Tan, Y.; Xu, L.; McIntyre, R.S.; Choo, F.N.; Tran, B.; Ho, R.; Sharma, V.K.; et al. A longitudinal study on the mental health of general population during the COVID-19 epidemic in China. Brain Behav. Immun. 2020, 87, 40-48. [CrossRef]

10. Tremblay, M.S.; Carson, V.; Chaput, J.P.; Connor Gorber, S.; Dinh, T.; Duggan, M.; Faulkner, G.; Gray, C.E.; Gruber, R.; Janson, K.; et al. Canadian 24-Hour movement guidelines for children and youth: An integration of physical activity, sedentary behaviour, and sleep. Appl. Physiol. Nutr. Metab. 2016, 41, S311-S327. [CrossRef] [PubMed]

11. Katzmarzyk, P.T; Staiano, A.E. Relationship between meeting 24-hour movement. guidelines and cardiometabolic risk factors in children. J. Phys. Act. Health 2017, 14, 779-784. [CrossRef] [PubMed] 
12. Roman-Viñas, B.; Chaput, J.P.; Katzmarzyk, P.T.; Fogelholm, M.; Lambert, E.V.; Maher, C.; Maia, J.; Olds, T.; Onywera, V.; Sarmiento, O.L.; et al. Proportion of children meeting recommendations for 24-hour movement guidelines and associations with adiposity in a 12-country study. Int. J. Behav. Nutr. Phys. Act. 2016, 13, 123. [CrossRef] [PubMed]

13. Carson, V.; Chaput, J.P.; Janssen, I.; Tremblay, M.S. Health associations with meeting new 24-hour movement guidelines for Canadian children and youth. Prev. Med. 2017, 95, 7-13. [CrossRef] [PubMed]

14. Janssen, I.; Roberts, K.C.; Thompson, W. Is adherence to the Canadian 24-hour movement behaviour guidelines for children and youth associated with improved indicators of physical, mental, and social health? Appl. Physiol. Nutr. Metab. 2017, 42, 725-731. [CrossRef] [PubMed]

15. GBD 2015 Obesity Collaborators; Afshin, A.; Forouzanfar, M.H.; Reitsma, M.B.; Sur, P.; Estep, K.; Lee, A.; Marczak, L.; Mokdad, A.H.; Moradi-Lakeh, M.; et al. Health Effects of Overweight and Obesity in 195 Countries over 25 Years. N. Engl. J. Med. 2017, $377,13-27$.

16. Gregg, E.W.; Shaw, J.E. Global Health Effects of Overweight and Obesity. N. Engl. J. Med. 2017, 377, 80-81. [CrossRef]

17. Ministry of Education. School health statistics, Annual Report of School Health Statistics Research. Available online: 20200325 -mxt_chousa01-20200325104819_1-1-1(7).Pdf (accessed on 27 September 2021). (In Japanese).

18. Reilly, J.J.; Kelly, J. Long-term impact of overweight and obesity in childhood and adolescence on morbidity and premature mortality in adulthood: Systematic review. Int. J. Obes. 2011, 35, 891-898. [CrossRef] [PubMed]

19. Cheung, Y.B.; Machin, D.; Karlberg, J.; Khoo, K.S. A longitudinal study of pediatric body mass index values predicted health in middle age. J. Clin. Epidemiol. 2004, 57, 1316-1322. [CrossRef] [PubMed]

20. Xiang, M.; Zhang, Z.; Kuwahara, K. Impact of COVID-19 pandemic on children and adolescents' lifestyle behavior larger than expected. Prog. Cardiovasc. Dis. 2020, 63, 531-532. [CrossRef]

21. Moore, S.A.; Faulkner, G.; Rhodes, R.E.; Brussoni, M.; Chulak-Bozzer, T.; Ferguson, L.J.; Mitra, R.; O’Reilly, N.; Spence, J.C.; Vanderloo, L.M.; et al. Impact of the COVID-19 virus outbreak on movement and play behaviours of Canadian children and youth: A national survey. Int. J. Behav. Nutr. Phys. Act. 2020, 17, 85. [CrossRef] [PubMed]

22. Rundle, A.G.; Park, Y.; Herbstman, J.B.; Kinsey, E.W.; Wang, Y.C. COVID-19-related school closings and risk of weight gain among children. Obesity 2020, 28, 1008-1009. [CrossRef] [PubMed]

23. Pietrobelli, A.; Pecoraro, L.; Ferruzzi, A.; Heo, M.; Faith, M.; Zoller, T.; Antoniazzi, F.; Piacentini, G.; Fearnbach, S.N.; Heymsfield, S.B. Effects of COVID-19 lockdown on lifestyle behaviors in children with obesity living in Verona, Italy: A longitudinal study. Obesity 2020, 28, 1382-1385. [CrossRef] [PubMed]

24. Booth, M.L.; Okely, A.D.; Chey, T.; Bauman, A. The reliability and validity of the physical activity questions in the WHO health behaviour in school children (HBSC) survey: A population study. Br. J. Sports Med. 2001, 35, 263-267. [CrossRef] [PubMed]

25. Tanaka, C.; Cyan, A.; Minoru, T.; Tim, O.; Natasha, S.; Maki, T.; Shigeho, T. The validity of the Japanese version of physical activity questions in the who health behaviour in school-aged children (HBSC) Survey. Res. Exerc. Epidemiol. 2017, $19,93-101$.

26. The Sedentary Behavior Research Network (SBRN). Consensus Definitions. Available online: https://www.sedentarybehaviour. org/sbrn-terminology-consensus-project (accessed on 23 August 2021).

27. Kim, H.; Ma, J.; Harada, K.; Lee, S.; Gu, Y. Associations between adherence to combinations of 24-h movement guidelines and overweight and obesity in Japanese preschool children. Int. J. Env. Res. Public Health 2020, 17, 9320. [CrossRef]

28. WHO Multicentre Growth Reference Study Group. WHO child growth standards based on length/height, weight and age. Acta Pediatr. Suppl. 2006, 450, 76-85.

29. Barlow, S.E.; Expert Committee. Expert committee recommendations regarding the prevention, assessment, and treatment of child and adolescent overweight and obesity: Summary report. Pediatrics 2007, 4, S164-S192. [CrossRef]

30. Blaszczyk-Bebenek, E.; Jagielski, P.; Boleslawska, I.; Jagielska, A.; Nitsch-Osuch, A.; Kawalec, P. Nutrition behaviors in Polish adults before and during COVID-19 lockdown. Nutrients 2020, 12, 3084. [CrossRef] [PubMed]

31. Park, J.H.; Yoo, E.; Kim, Y.; Lee, J.M. What Happened Pre- and during COVID-19 in South Korea? Comparing Physical Activity, Sleep Time, and BodyWeight Status. Int. J. Env. Res. Public Health 2021, 18, 5863. [CrossRef] [PubMed]

32. Woolford, S.J.; Sidell, M.; Li, X.; Else, V.; Young, D.R.; Resnicow, K.; Koebnick, C. Changes in Body Mass Index Among Children and Adolescents During the COVID-19 Pandemic. JAMA 2021, 326, 1434-1436. [CrossRef] [PubMed]

33. Jia, P.; Zhang, L.; Yu, W.; Yu, B.; Liu, M.; Zhang, D.; Yang, S. Impact of COVID-19 lockdown on activity patterns and weight status among youths in China: The COVID-19 Impact on Lifestyle Change Survey (COINLICS). Int. J. Obes. 2021, 45, 695-699. [CrossRef]

34. Tanaka, C.; Tremblay, M.S.; Okuda, M.; Inoue, S.; Tanaka, S. Proportion of Japanese primary school children meeting recommendations for 24-h movement guidelines and associations with weight status. Obes. Res. Clin. Pr. 2020, 14, 234-240. [CrossRef] [PubMed]

35. Lopez-Gil, J.F.; Tremblay, M.S.; Brazo-Sayavera, J. Changes in healthy behaviors and meeting 24-h movement guidelines in Spanish and Brazilian preschoolers, children and adolescents during the COVID-19 lockdown. Children 2021, 8, 83. [CrossRef] [PubMed]

36. Guo, Y.F.; Liao, M.Q.; Cai, W.L.; Yu, X.X.; Li, S.N.; Ke, X.Y.; Tan, S.X.; Luo, Z.Y.; Cui, Y.F.; Wang, Q.; et al. Physical activity, screen exposure and sleep among students during the pan-demic of COVID-19. Sci. Rep. 2021, 11, 8529. [CrossRef] [PubMed] 
37. Guan, H.; Okely, A.D.; Aguilar-Farias, N.; Del Pozo Cruz, B.; Draper, C.E.; El Hamdouchi, A.; Florindo, A.A.; Jáuregui, A.; Katzmarzyk, P.T.; Kontsevaya, A.; et al. Promoting Healthy Movement Behaviours among Children during the COVID-19 Pandemic. Lancet Child Adolesc. Health 2020, 4, 416-418. [CrossRef]

38. Fjortoft, I. Landscape as Playscape: The effects of natural environments on children's play and motor development. Child. Youth Environ. 2004, 14, 21-44.

39. Bentlage, E.; Ammar, A.; How, D.; Ahmed, M.; Trabelsi, K.; Chtourou, H.; Brach, M. Practical recommendations for maintaining active lifestyle during the COVID-19 pandemic: A systematic literature review. Int. J. Env. Res. Public Health 2020, 17, 6265. [CrossRef] [PubMed]

40. Kim, H.; Ma, J.; Maehashi, A. Factors impacting levels of physical activity and sedentary behavior among young children: A literature review. Int. J. Appl. Sports Sci. 2017, 29, 1-12.

41. Yang, S.; Guo, B.; Ao, L.; Yang, C.; Zhang, L.; Zhou, J.; Jia, P. Obesity and activity patterns before and during COVID-19 lockdown among youths in China. Clin. Obes. 2020, 10, e12416. [CrossRef]

42. Iannotti, R.J.; Kogan, M.D.; Janssen, I.; Boyce, W.F. Patterns of adolescent physical activity, screen-based media use, and positive and negative health indicators in the US and Canada. J. Adolesc. Health 2009, 44, 493-499. [CrossRef] [PubMed]

43. Riazi, N.A.; Wunderlich, K.; Gierc, M.; Brussoni, M.; Moore, S.A.; Tremblay, M.S.; Faulkner, G. “You Can't Go to the Park, You Can't Go Here, You Can't Go There": Exploring Parental Experiences of COVID-19 and Its Impact on Their Children's Movement Behaviours. Children 2021, 8, 219. [CrossRef] [PubMed]

44. Paterson, D.C.; Ramage, K.; Moore, S.A.; Riazi, N.; Tremblay, M.S.; Faulkner, G. Exploring the impact of COVID-19 on the movement behaviors of children and youth: A scoping review of evidence after the first year. J. Sport Health Sci. 2021, 21, S2095-S2546. [CrossRef] [PubMed]

45. Kim, H.; Ma, J.; Lee, S.; Gu, Y. Change in Japanese children's 24-hour movement guidelines and mental health during the COVID-19 pandemic. Sci. Rep. 2021, 11, 22972.

46. Zhou, S.J.; Zhang, L.G.; Wang, L.L.; Guo, Z.C.; Wang, J.Q.; Chen, J.C.; Liu, M.; Chen, X.; Chen, J.X. Prevalence and sociodemographic correlates of psychological health problems in Chinese adolescents during the outbreak of COVID-19. Eur. Child Adolesc. Psychiatry 2020, 29, 749-758. [CrossRef] [PubMed]

47. Komada, Y.; Ishibashi, Y.; Hagiwara, S.; Kobori, M.; Shimura, A. A Longitudinal Study of Subjective Daytime Sleepiness Changes in Elementary School Children Following a Temporary School Closure Due to COVID-19. Children 2021, 8, 183. [CrossRef] [PubMed]

48. Paruthi, S.; Brooks, L.J.; Ambrosio, C.D.; Hall, W.A.; Kotagal, S.; Lloyd, R.M.; Malow, B.A.; Maski, K.; Nichols, C.; Quan, S.F.; et al. Recommended Amount of Sleep for Pediatric Populations: A Consensus Statement of the American Academy of Sleep Medicine. J. Clin. Sleep Med. 2016, 12, 785-786. [CrossRef]

49. Treutler, C.M.; Epkins, C.C. Are discrepancies among child, mother, and father reports on children's behavior related to parents' psychological symptoms and aspects of parent-child relationships? J. Abnorm. Child Psychol. 2003, 31, 13-27. [CrossRef] 